\title{
Status of tissue engineering and regenerative medicine in Iran and related advanced tools: Bioreactors and scaffolds
}

\author{
Anneh Mohammad Gharravi ${ }^{1}$, Mahmoud Orazizadeh ${ }^{1 *}$, Mahmoud Hashemitabar ${ }^{1}$, \\ Karim Ansari-Asl ${ }^{2}$, Salem Banoni ${ }^{3}$, Ali Alifard ${ }^{4}$, Sina Izadi ${ }^{4}$ \\ ${ }^{1}$ Cellular and Molecular Research Center, Department of Anatomical Sciences, Faculty of Medicine, Ahvaz Jundishapour University \\ of Medical Sciences, Ahvaz, Iran \\ ${ }^{2}$ Electrical Engineering Department, Engineering Faculty, Shahid Chamran University, Ahvaz, Iran \\ ${ }^{3}$ Computer Engineering Department, Engineering Faculty, Shahid Chamran University, Ahvaz, Iran \\ ${ }^{4}$ Mechanical Engineering Department, Engineering Faculty, Shahid Chamran University, Ahvaz, Iran \\ Email: ㄹ﹎orazizadeh@yahoo.com
}

Received 21 November 2011; revised 6 January 2012; accepted 18 January 2012

\begin{abstract}
Because of increased need to tissue and organ transplantation, tissue engineering (TE) researches have significantly increased in recent years in Iran. The present study explored briefly the advances in the TE approaches in Iran. Through comprehensive search, we explored main TE components researches include cell, scaffold, growth factor and bioreactor conducted in Iran. The field of $\mathrm{TE}$ and regenerative medicine in Iran dates back to the early part of the 1990 decade and the advent of stem cell researches. During past two decades, Iran was one of leader in stem cell research in Middle East. The next major step in TE was application and fabrication of scaffolds for TE in the early 2000s with focused on engineering bone and nerve tissue. Iranian researchers extensively used natural scaffolds in their studies and hybridized natural polymers and inorganic scaffolds. There are many universities and government research institutes are conducting active research on tissue-engineering technologies. Limitations to TE in Iran include property design and validation of bioreactors. In conclusion, in the last few years, fields of tissue engineering and regenerative medicine such as stem cell technology and scaffolds have progressed in Iran, but one of the biggest challenges for $\mathrm{TE}$ is bioreactors researches.
\end{abstract}

Keywords: Iran; Tissue Engineering; Cell; Scaffold; Signal; Bioreactor

\section{INTRODUCTION}

Because of increased mean life expectancy, Road traffic injuries (RTIs) and disabilities resulted from Iran-Iraq

\footnotetext{
"Corresponding author.
}

war the loss and damage of tissue is a great challenge for public health of Iran [1].

Road traffic injuries (RTIs) are a major global public health problem [2-4]. In 2005, 500,000 Iranians injured annual in road traffic crashes, and the death and injury rate is the highest of any country in the world for which reliable estimates are available [5,6]. In other study, Towhidpour and Amiruddin indicated that in 2009, road fatality rates were 30.96 per 100,000 population while middle-income countries had 19.5 per 100,000 population roads traffic fatality rates. This study demonstrated that the rate of road injuries between 2007 and 2009 increased by $10 \%$ when compared with 2005 [7].

8-year of the Iran-Iraq war victims are another great challenge for public health of Iran. During the war (1980 to 1988), physical and psychological disability of approximately 500,000 people rapidly increased need to tissue and organ transplantation [8]. However, low availability of compatible donor's severely limited transplantation of tissues or organs for these patients [9]. Thus, new strategy and therapy concepts for repair of diseased and damaged tissue are required. Therefore, biomedical research activities such as TE in Iran have significantly increased in recent years. Various sources of funding especially through the Iranian government in the recent years have been influential in increasing TE /biomedical researches.

\section{TISSUE ENGINEERING}

TE is an alternative to organ transplantation. A more commonly used definition of TE , as coined by Langer and Vacanti, is "an interdisciplinary field that applies the principles of engineering and life sciences toward the development of biological substitutes that restore, maintain, or improve function of a tissue or a whole organ" $[10,11]$. Many researchers have defined six components 
for TE, namely, cells, scaffolds, bioreactors, stimulation (mechanical etc.), cell-cell contact and chemical factors (growth factors, etc.)

\section{PAST, PRESENT AND FUTURE OF TE IN IRAN}

\subsection{History of Ancient TE and Medicine in Iran}

Iran has a long history of scientific achievements and prior to Islam, Iran was a leader in mathematics and astronomy. Furthermore, regenerative medicine has a long history in Iran. As reported in archaeological literatures, the earliest artificial eye (5000-year-old golden artificial eye) found by an Iranian archaeologist in Shahr-i-Sokhta. Shahr-i-Sokhta (Burnt City) is in the Sistan desert on the Iranian-Afghan border [12] (Figure 1).

The field of TE and regenerative medicine in Iran dates back to the early part of the 1990 decade and the advent of stem cell researches, i.e. the production of stem cell line. The Royan Institute is Iran's leading stem cell research center. The institute established in 1991 and approved by the Iranian Ministry of Health in 1998. The institute has been main forum presenting stem cell research activities for recent years [13].

\subsection{0 to Present}

The next major step in TE progress in Iran was application and fabrication of scaffolds for TE in the early 2000s. The earliest attempt carry out TE effort was reported in the Iranian Polymer Journal in the year 2000 [14]. It was not until 2000-2010, however, that one began to see more and more researches in this emerging field. This is when many of the pioneers in TE research began to make their mark [15-18]. It is important to consider that the focus of Iranian researchers was on engineering bone and

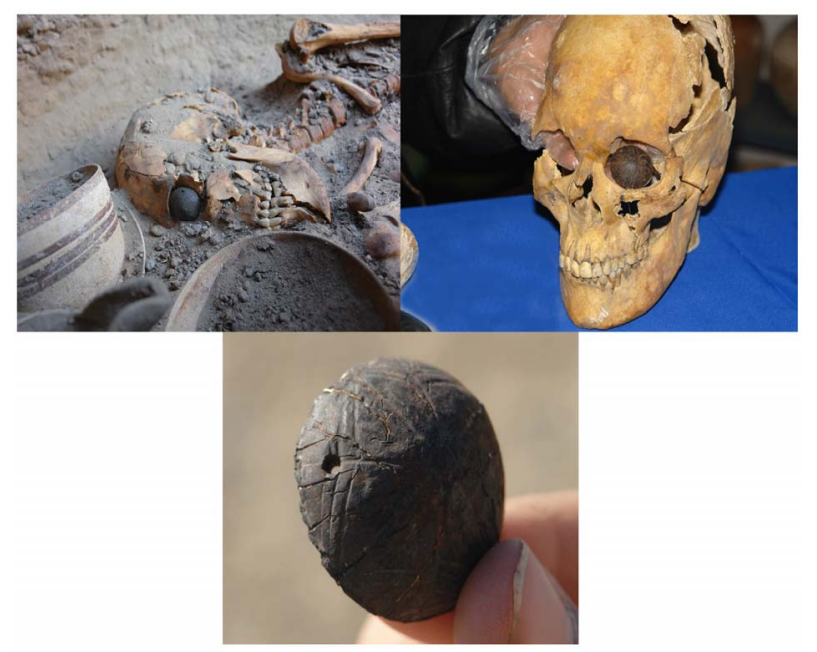

Figure 1. The earliest artificial eye was found by an Iranian archaeologist in Shahr-i-Sokhta, Iran. nerve tissue, by an integrated use of stem cells and biomaterial scaffolds. This is due, at least in part, to high rate of trauma and spinal injuries during Iran-Iraq war [2-8] and the advent of stem cell research.

In attempts to engineer other tissues, such as skin, cartilage, and hepatic and even in efforts to recreate neo tissues, several promising studies conducted. Recently Iranian researchers have extensively used scaffolds for TE [19-23]. Long-term goals of Iranian researchers are to engineer tissue grafts for application in regenerative medicine, develop enabling technologies for stem cell research, and design high-fidelity models for studies of tissue development, remodeling, and disease. Therefore, the number of Iranian academic and industrial groups studying TE is rapidly increasing, leading to more journal articles on TE (Figure 2).

There are many universities and government research institutes in Iran, such as Royan Institute [24-26], Amirkabir University [19,20,27-30] , Pasteur Institute of Iran [31-34], University of Tehran [20,35], Tarbiat Modares University [20,36-39], Shaheed Beheshti University of Medical Sciences [40,41,43,45], Tehran University of Medical Sciences [42,44], National Institute for Genetic Engineering [46], Islamic Azad University [47-49], Iran University of Science and Technology [50,51] and Iran Polymer and Petrochemical Institute [52,53] are conducting active research on the development of artificial organs based on tissue-engineering technologies.

\subsection{Future}

The global effort will write the future history of TE and regenerative medicine in Iran. As we look into this future, in some cases, the development of TE will made the advances in treatment or therapy will be made through the development of tissue engineering.

In following sections, we review researches based on TE component in detail.

\section{CELLS}

In this section, we will focus on a number of different sources and most cells used by Iranian researchers for tissue repair and regeneration each with its own advantages and disadvantages.

\subsection{Mature Cells}

Isolated cells from tissue biopsies can potentially use for TE. Mature cells are the most desirable with regard to immunological compatibility. However, they are probably not the best cell source for tissue repair. Because they are differentiated and post-mitotic cell and some cell types have the tendency to de-differentiate during ex vivo cultivation [54]. However, since a study suggested that intra-epidermal injection of dissociated epidermal 


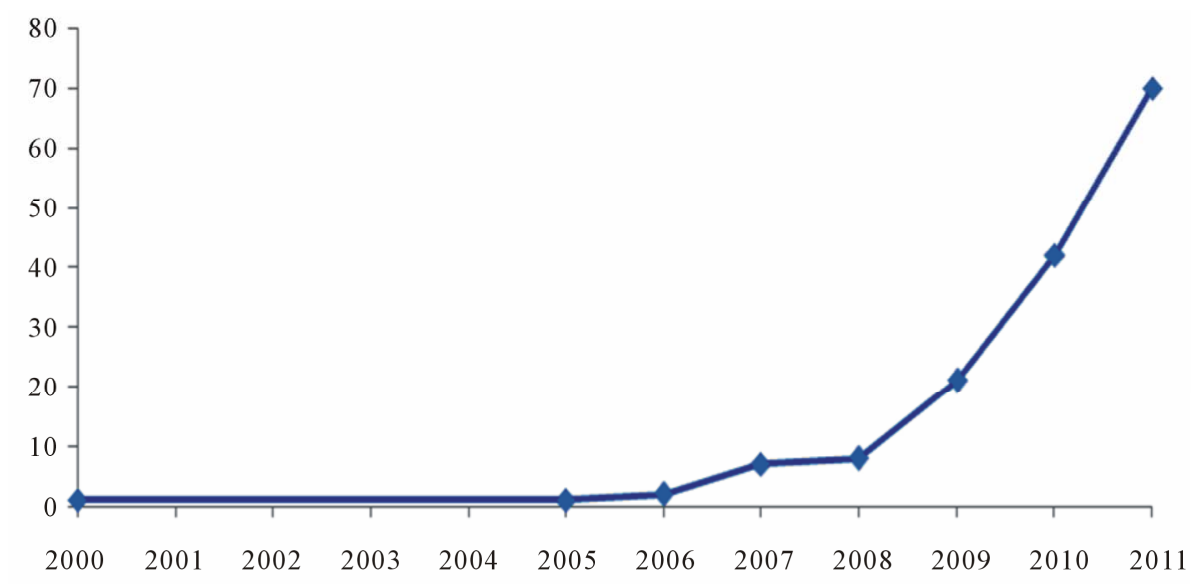

Figure 2. Trend and number of published articles related to TE researchers in Iran that indexed in Pub Med database from 2000 to June 2011.

cells into the lesions of stable vitiligo patients, is an effective, simple and safe therapeutic option for stable vitiligo lesions [55], several researchers in Iran investigated TE with mature cells [25,32].

\subsection{Stem Cells}

Stem cells are precursor cells that possess certain characteristics. These characteristics serve to distinguish them from other cell types. Definition of Stem cells done by two properties: self renewal and differentiation [56]. Stem cells can be classified according to developmental potential and origin. Depending to measures of stem cell potency, the cells may be classified into tot potential, pluripotential, multipotential, and unipotential cells. Depending on their origin, stem cells are classified into embryonic stem (ES) cells, embryonic germ (EG) cells, embryonal carcinoma (EC) cells, trophoblast stem (TS) cells, and foetal stem cells [57]. Since Iran is one of leader in stem cell research in Middle East here, we review most stem cells used by Iranian researchers.

\subsubsection{Adult Stem Cells (ASCs)}

Adult stem cells are undifferentiated cells, which reside in differentiated tissues. Many adult tissues contain the stem cells that can be isolated. They are responsible for growth, tissue maintenance, regeneration, and repair of diseased or damaged tissues. In general, there are two distinct types of ASC within the bone marrow the hematopoietic stem cell (HSC) and bone marrow stem cell (BMSC) [58].

\subsubsection{Mesenchymal Stem Cells (MSCs)}

There are some reports that when compared, the differentiating potential of these cells for osteogenic capacity is greater than Unrestricted Somatic Stem Cells (USSCs) and Adipose stem cells (ASCs) [42-68]. A clinical study revealed that MSCs loaded to the biphasic scaffold (betatricalcium phosphate/hydroxyapatite), may enhance bone formation in the maxillary sinus area for sinus elevation [44]. In other clinical study patients with unilateral alveolar cleft, treated with the composite scaffold of demineralized bone mineral and calcium sulphate (Osteoset) loaded with mesenchymal stem cells (MSCs). Computed tomograms showed regenerated bone after 4 months [41].

Mohammadi and colleagues reported that culture of MSCs in Nanofibrous poly (epsiloncaprolactone)/poly (vinyl alcohol)/chitosan hybrid upregulated the expression of early and late markers of osteoblastic differentiation [67].

The other study investigated the effect of transplantation MSCs induced into endoderm and early hepatic cells in streptozotocin (STZ)-induced diabetic mice, and suggested that MSCs are suitable candidates for cell-based therapy of diabetes mellitus [63]. Further study revealed that the engineered nanofibrous scaffold Poly (epsiloncaprolactone), collagen and polyethersulfone) is a conductive matrix, which supports and enhances MSC development into functional hepatocyte-like cells [39]. Furthermore, in a clinical experiment, human mesenchymal stem cells (MSCs) from eye conjunctiva stromal cells were differentiated into dopaminergic neurons. The MSCs were treated with general neurogenic medium expressed of dopaminergic neuron genes such as $\mathrm{TH}$, Ptx3, and Nurr1. Therefore, was concluded that CJMSCs might be a suitable and available source for cell transplantation therapy for the central system diseases such as Parkinson's disease (PD) [66]. In other in vitro neurogenic study of MSCs, the two-stage induction protocol resulted in transdifferentiation of BMSCs into GABAergic cells with synaptic release upon stimulation [68]. Also Soleimani and colleagues reported that poly L-lactic acid (PLLA) could be used to support neurogenic and 
hinder dopaminergic differentiation of conjunctiva mesenchymal stem cells (CJMSCs) in vitro [37]. Meanwhile,

Ahmadbeigi and colleagues for first time reported spontaneous, non-tumorigenic immortalization of BMMSC in rabbits [62]. Therefore, Ghaedi and colleagues proposed that hMSCs may serve as an effective platform for the targeted delivery of therapeutic proteins to cancer sites [60]. The other study revealed that applying appropriate loading treatment on hMSCs could enhance proliferation capability, and produce functional SMCs for engineered tissues [29]. Mohajeri and colleagues improved mechanical properties of collagen to enable mesenchymal stem cells to positively improve their proliferation and differentiation [38].

\subsubsection{Adipose Stem Cells (ASCs)}

Adipose tissue is one of the richest sources of MSC's [64]. When compared to bone marrow, there are more than 500 times more stem cells in 1 gram of fat when compared to 1 gram of aspirated bone marrow. Studies showed that surfaces containing HGF co-printed with ECM proteins can be used to differentiate mesenchymal stem cells such as ASCs into hepatocyte-like cells [61].

\subsubsection{Embryonic Stem (ES) Cells}

Pluripotential embryonic stem cells derived from the inner cell mass of the blastocyst. Embryonic stem cells do not exist in the body. When cells are isolated, they can be massively expanded in the laboratory, while maintaining their pluripotency (self-renewal), then differentiated.

Researchers examined the differentiating potential of human embryonic stem cells (hESCs) into hepatocytes. Results revealed that the differentiated cells give rise to cells displaying morphological features, gene expression patterns, and metabolic activities characteristic of hepatocytes. Authors proposed that hESCs may provide a source of differentiated cells for treatment of liver diseases [15].

Several Iranian researchers differentiated ESCs into neural cells in defined adherent culture by retinoic acid and concluded that ESCs seeded in scaffold such as polyL-lysine-coated PLGA and collagen can be as a model system for nerve tissue engineering, thus may provide a new approach for the repair of spinal cord injury [24, 26,69].

\subsubsection{Placenta Derived Stem Cells (Amniotic)}

Up to ten times as many, stem cells can be harvested from a placenta as from cord blood for differentiation. Niknejad and coworkers reviewed properties of the amniotic membrane for potential use in tissue engineering [43].

\subsubsection{Unrestricted Somatic Stem Cells (USSCs)}

These non-hematopoietic stem cells in cord blood (CB) appear not to be simply MSCs. The frequency of these stem cells is also higher in CB than in adult bone marrow, probably due to the very rapid growth .USSCs have the potential to differentiate into mesodermal, ectodermal as well as into endodermal cells. Thus, Iranian researchers investigated differentiating potential of the cells into mesodermal cells such as bone. Therefore, the capacity of fabricated scaffolds for bone formation was investigated in vitro using USSCs under osteogenic induction. The authors introduced a new combination of stem cell-scaffold constructs with desired characteristics for application in bone tissue engineering [19,20,34,35]. In other attempt for investigate differentiating potential of the cells into endodermal cells, Hashemi and colleagues showed that hepatocyte-like cells differentiated from USSCs on the PCL nanofiber scaffold can be candidate for tissue engineering and cell therapy of hepatic tissues [23].

\section{SCAFFOLDS}

\subsection{Definition and Roles in TE}

The officially accepted definition considers a scaffold as a "support, delivery vehicle or matrix for facilitating the migration, binding or transport of cells or bioactive molecules used to replace, repair or regenerate tissues" [70].

The functions of the scaffold are to provide a threedimensional (3D) cell culture template that can induce seeded cells to regenerate full tissues and to degrade at a known, controlled rate. Thus, the important roles played by scaffolds TE are to mimic the functions of native ECM, at least partially [71].

\subsection{Property and Types}

The scaffold for TE should facilitate cell adhesion and promote cell growth. Furthermore, the scaffold should be biocompatible, biodegradable, highly porous with, mechanically strong, and malleable [72,73].

Many types of biomaterials and scaffolding can be used to make scaffolds for TE. Here we review most biomaterial and scaffolding used by Iranian researchers.

\subsubsection{Pre-Made Porous Scaffolds for Cell Seeding}

They can be classified into two categories according to their sources, namely natural (e.g. collagen) and synthetic biomaterials (e.g. polyglycolide).

Due to their biocompatibility, relative abundance and commercial availability, and ease of processing, Iranian researchers extensively used natural scaffold in their studies $[21,22,46,69]$. Hatami and colleagues investi- 
gated generation of hESC-derived neural precursor as neural-like tubes in adherent and feeder-free hESC. They reported that hESC-NPC transplants in collagen scaffolds, promote recovery in injured rat spinal cord [22]. Similar results reported by Baharvand and colleagues [69]. In other attapmt, Pajoum Shariati and colleagues developed a culture method for propagation of keratinocytes and fibroblasts isolated from human neonatal foreskin. They used modified method of freeze gelation for fabrication of relevant biodegradable and biocompatible collagenchitosan porous scaffold with improved biostability. Findings these procedures introduced a potential source of living skin for grafting in vivo [21]. Also, it was reported that collagen gel can be used as a bio-scaffold for the production of engineered sperm analogues and proposed that [46].

Synthetic scaffold are largely divided into two categories biodegradable and nonbiodegradeable. Some nonbiodegradeable include polyvinylalcohol (PVA), etc. Some synthetic biodegradable polymers are the family of poly ( $\alpha$-hydroxy esters) such as polyglycolide (PGA), polylactide (PLA), etc. In spite, synthetic biomaterials have better controlled physical and mechanical but because of difficulties in attachment and growth on these materials, biocompatibility becomes the major issue. Several studies investigated TE approaches with the polymers [18,23,31,33,47-49,53,65,74,77]. Shariatpanahi and coworkers investigated the effect of grafting $\mathrm{N}$-vinyl-2-pyrrolidone (NVP) onto polyvinyl alcohol (PVA). PVA scaffolds were prepared by freeze-thaw and progen (glycerol) methods. Cell attachment was optimal for the introduced scaffolds [18].

In other study biocompatibility of $\beta$-TCP/HDPEUHMWPE nanocomposite as a new bone substitute material was attempted by using highly purified human osteoblast cells. Results indicated that the nanosized $\beta$ TCP/HDPE-UHMWPE blend composites could be potential scaffold, which is used in bone tissue engineering [31]. Heidarkhan Tehrani and colleagues hypothesized to be able to quantify the efficacy of fibrous scaffolds by considering the integration of porosity and interconnecttivity of the pores [74]. In other study polyethersulfone (PES) nanofibrous scaffolds were prepared by fine tuning of electrospinning parameters and were evaluated for wound dressing applications. Epithelial regeneration was expeditiously accelerated under PES as compared with Vaseline gauze. Based on results, it was concluded that the biocompatible PES nanofibers can effectively be used as a dressing to accelerate wound healing [77].

\subsubsection{Decellularized ECM}

This scaffolding approach removes the allogenic or xenogenic cellular antigens from the tissues as but preserves the ECM components. In a study, decellularized human amniotic membrane (HAM) revealed a well-designed growth pattern of human bladder smooth muscle cells (HBSMCs) with abundant cell-to-cell adhesions [50].

\subsubsection{Cell Sheets with Self-Secreted ECM}

This scaffolding represents an approach where cells secrete their own ECM upon confluence and are harvested without the use of enzymatic methods. Several researchers examined harvesting of epithelial cell sheet to support for epithelial cell grafting especially cornea regeneration [75]. Biazar and coworkers investigated the effect of $\alpha \gamma$-pre-irradiation dose of radiation under appropriate temperature and grafting conditions onto a polystyrene cell culture dish. Results indicated that the cells detached spontaneously without using enzymes, and proved that this type of grafted material has potential as a biomaterial for cell sheet engineering [76].

\subsubsection{Cell Encapsulation in Polymer Gels}

Cell encapsulation is a process entrapping living cells within hydrogel and provides cells with a three-dimensional environment similar to that experienced in vivo. Naturally, occurring polysaccharides derived from algae, sodium alginate is the most commonly used material by Iranian researchers [25].

\subsubsection{Hybridization of Synthetic/Natural Polymers}

Synthetic scaffolds lack good cell interactions. In contrast, natural polymer has the potential advantages of specific cell interactions, but the scaffolds have poor mechanical strength. Therefore, Iranian researchers hybridized natural polymers and inorganic scaffold to combine the advantageous properties of both constitutes [17,20,28,37-39,50-52,78,79]. In study of Seyedjafari and coworker, nanohydroxyapatite (n-HA) was coated on poly (l-lactide) (PLLA) nanofibers. The n-HA/PLLA electrospun scaffold showed the capacity for ectopic bone formation in the absence of exogenous cells [20]. In similar study, a nanostructured scaffold was designed for bone repair using hydroxyapatite (HA) and gelatin (GEL) as its main components. Results showed that nano-HA powders can be synthesized and used to make 3-dimensional HA/GEL nanocomposites in any desired shape, with mechanical properties comparable to spongy bone [28]. Also Aboudzadeh and coworkers fabricated scaffolds based on polymer/bioceramic composites. They fabricated and characterized poly (D, L-lactide coglycolide)/hydroxyapatite nanocomposite scaffolds for bone tissue regeneration [51]. Likewise Hajiali and colleagues prepared poly (3-hydroxybutyrate) with bioglass nanoparticles by the salt leaching processing technique, as a nanocomposite scaffold [78]. In other attempts to improve mechanical properties of collagen, Mohajeri and 
coworkers prepared a novel porous scaffold for bone tissue engineering with collagen sponge reinforced by polypropylene/polyethylene terephthalate (PP/PET) fibers [38]. In other study a scaffold composed of Poly (epsiloncaprolactone), collagen and polyethersulfone was fabricated by the electrospinning technique which supports and enhances MSC development into functional hepatocyte-like cells [39]. To manufacture a new hybrid sponge scaffold, Eslaminejad and colleagues prepared a composite of beta-tricalcium phosphate-alginate-gelatin. Results indicated that the scaffolds were cell compatible and, more importantly, possess some osteo-inductive properties [79].

\section{STIMULATION (MECHANICAL)}

Mechanical stimulation plays a critical role in natural tissue development. This stimulus generally applied by bioreactor to composition and ultrastructural distribution of the extracellular matrix and thus the structural integrity of TE constructs. Mechanical stimuli are particularly important for tissues that support mechanical loads in vivo, including bone, cartilage, muscle, and vasculature [16,29,80-82]. Therefore, Ghazanfari and coworkers investigated influence of cyclic stretch on proliferation of hMSCs, alignment of actin filaments, and consequent differentiation to SMCs. Results indicated promoted proliferation of hMSCs by cyclic strain, and cyclic stretch regulated smooth muscle alpha-actin, and reoriented actin fibers [79]. Orazizadeh and coworkers to identify whether integrin-associated protein (CD47/IAP), is expressed by chondrocytes and whether it may regulate integrin-dependent mechanotransduction, studied cells in a resting state or following mechanical stimulation at $0.33 \mathrm{~Hz}$. Results indicated that CD47 associated with alpha 5 integrin and regulated responses of human articular chondrocytes to mechanical stimulation [81-83].

\section{CHEMICAL FACTORS}

A number of growth factors like platelet-derived growth factor (PDGF), hepatocyte growth factor (HGF) and fibroblast growth factor (FGF) explored for their effects on TE $[40,61,63,84]$. These factors were investigated independently and synergistically, with outcomes dependent on cell type and culture conditions. A study Investigated differentiation factors such as retinoic acid (RA), basic fibroblast growth factor (bFGF) that influence neuronal markers expression in vitro from human amniotic epithelial cells. Results showed the capability of AECs to express neural cell markers and this ability is affected by some factors including serum, noggin, bFGF and RA [40]. The study of Ghaedi underscored the utility of growth factor-containing culture surfaces for stem cell differentiation. Bottom-up signaling from HGF-contain- ing surfaces promoted hepatic differentiation of mesenchymal stem cells [61]. Similar result gained about effect of hepatocyte growth factor (HGF) and fibroblast growth factor (FGF-4) on Mouse BMMSCs [63]. In addition, members of the Bone morphogenetic protein (BMP) family have been shown to play a major role in differentiation process. Results of Makoolati and coworkers suggest that BMP4 is an efficient inducer in primordial germ cell (PGC) derivation from mouse ESC [85].

\section{BIOREACTORS}

Bioreactor is defined as a means and model systems to generate and maintain a controlled culture environment to support investigations on cell function and tissue development.

\subsection{Role of Bioreactors in ex Vivo Engineering of 3D Tissues}

In general, the functions of a bioreactor are to enhance cell seeding and mass transfer within the culture medium and to provide tissues with hydrodynamic and/or mechanical stimulation [85].

\subsubsection{Cell Seeding on 3D Scaffolds}

Static cell seeding is by far the most commonly used seeding method. However, this loading of cells onto a scaffold leads to low seeding efficiencies and non-uniform cell distributions within scaffolds. Several studies reported that 3D-scaffold seeding in bioreactors resulted higher seeding efficiencies and more-uniform cell distributions [85].

\subsubsection{Increase of Mass Transport}

Static culture of tissues in Petri dish leads to construct with hypoxic, necrotic center, surrounded by a rim of viable cells. Therefore, as tissue constructs should have larger dimensions, mass transfer limitations represent one of the greatest engineering challenges. Bioreactors have been used successfully to increase the mass transport of nutrients and oxygen [85].

\subsubsection{Mechanical Conditioning}

Mechanical conditioning has been employed to induce, accelerate, and/or enhance tissue formation. In addition, the mechanically active environment present in bioreactors mediates the effectiveness of three-dimensional (3D) scaffolds for tissue engineering [85].

In comparison to developed countries, design and validation of a bioreactor research is harder for scientists in developing countries such as Iran. Among many reasons, scientists in developing countries struggle more for provision of proper set-up and research funding. Consequently, Iranian scientists published a limited articles 
related to bioreactor in biomedical journals [86-89]. In a study, Packed-bed bioreactor was used by Golmakany and coworkers for continuous production of monoclonal antibody [86]. Amoabediny and coworkers equipped the special shake flasks with oxygen sensors and then developed an unsteady-state model for a biological system in miniaturized bioreactors [89]. In other attempts Amoabediny and coworkers presented a new online monitoring method for the determination of the $\mathrm{CO}_{2}$ sensitivity of microorganisms in shaken bioreactors. The major advantage of the new methods was the possibility to determine the metabolic activity, regardless of manual sampling $[87,88]$.

\section{CONCLUSION}

Injury or a disease in growing countries such as Iran has significantly increased in the past few decades that increased need to tissue and organ transplantation. However, low availability of compatible donor's severely limited transplantation of tissues or organs. Thus, biomedical research activities such as TE and new strategy and therapy concepts for repair of diseased and damaged tissue increased in recent years. Among components of $\mathrm{TE}$, Iranian researchers have great chance of providing stem cells due to governmental funding and supports. During the last years, stem cell researchers have found great public interest in Iran. In the scaffold field of TE, Iranian researchers used hybridization of natural polymers and inorganic scaffold to provide optimal scaffolds for TE. In particular, the researchers used hybridization of polymers to adhere, migrate, differentiation and synthesize new bone matrix. Despite its progress for studying stem cell and scaffold, limitations to TE in Iran include property design and validation of bioreactors. Therefore, one of the biggest challenges for TE in Iran is bioreactors researches.

\section{ACKNOWLEDGEMENTS}

This work is part of $\mathrm{PhD}$ thesis of Anneh Mohammad Gharravi. This work was funded by the cellular and molecular research center (CMRC), research deputy of Ahvaz Jundishapour University of Medical Sciences (AJUMS).

\section{REFERENCES}

[1] Lopez, D.A., Mathersm, C.D., Ezzati, M., Jamison, D.T. and Murray, C.J. (2006) Global and regional burden of disease and risk factors, 2001: Systematic analysis of population health data. Lancet, 367, 1747-1757. doi:10.1016/S0140-6736(06)68770-9

[2] Peden, M., Scurfield, R., Sleet, D., Mohan, D., Hyder, A.A., Jarawan, E. and Mathers, C. (2004) World report on road traffic injury prevention Geneva: World Health Organization.
[3] Murray, C.J.L. and Lopez, A.D. (1996) The global burden of disease: A comprehensive assessment of mortality and disability from diseases, injuries, and risk factors in 1990 and projected to 2020 Boston: Harvard School of Public Health.

[4] Kopits, E. and Cropperm, M. (2003) Traffic fatalities and economic growth Washington DC. Policy Research Working Paper No. 3035, The World Bank.

[5] Bhalla, K. (2007) Road traffic injury metrics recommended definitions. Harvard University Initiative for Global Health Road Traffic Injury Metrics Group, Cambridge.

[6] Bhalla, K., Naghavi, M., Shahraz, S., Bartels, D. and Murray, C.J. (2009) Building national estimates of the burden of road traffic injuries in developing countries from all available data sources: Iran. Injury Prevention, 15, 150-156. doi:10.1136/ip.2008.020826

[7] Pourrostam, T. and Ismail, A. (2011) Socio-economic consequences of traffic accidents in Iran. Australian Journal of Basic and Applied Sciences, 5, 897-901

[8] Noorbala, A.A. (2010) The organization and management of medical services to injured soldiers across the country and in the battlefields during the Iran-Iraq war. Archives of Iranian medicine, 13, 367-369.

[9] Chapekar, M.S. (2000) Tissue engineering: Challenges and opportunities. Journal of Biomedical Materials Research, 53, 617-620. doi:10.1002/1097-4636(2000)

[10] Meyer, U., Meyer. T., Handschel, J. and Wiesmann, H.P. (2009) Fundamentals of tissue engineering and regenerative medicine. Leipzig, Springer-Verlag, Berlin.

[11] Langer, R. and Vacanti, J.P. (1993) Tissue engineering. Science, 260, 920-926. doi: 10.1126/science.8493529

[12] Sajjadi, S.M.S. (2008) Shahri Sokhta's artificial eye, cultural heritage of Sistan \& Baluchistan. 1st Edition, Forohar, Tehran.

[13] Miremadi, T. (2010) Stem cell research and technology in Iran-Window of opportunity in the midst of international tension. Review of Policy Research, 27, 699-719. doi:10.1111/j.1541-1338.2010.00467.x

[14] Mirzadeh, H., Mohagheghi, M.A., Ahmadi, H., Mirkhani, H., Amanpour, S. and Salehian, P. (2000) Cartilage tissue engineering for ear as in rabbit model with perforated polyurethane prosthesis: In vivo assay. Iranian Polymer Journal, 9, 73-79.

[15] Baharvand, H., Hashemi, S.M., Kazemi Ashtiani, S. and Farrokhi, A. (2006) Differentiation of human embryonic stem cells into hepatocytes in 2D and 3D culture systems in vitro. The International journal of developmental biology, 50, 645-652. doi:10.1387/ijdb.052072hb

[16] Karbasi, S. (2006) Evaluation of hydrostatic pressure on metabolism of the articular chondrocytes seeded on biodegradable polyurethane as tissue engineering scaffold. World Congress on Medical Physics and Biomedical Engineering 2006 IFMBE. Proceedings, 14, 3382-3385.

[17] Eslaminejad, M.B., Mirzadeh, H., Mohamadi, Y. and Nickmahzar, A. (2007) Bone differentiation of marrow derived mesenchymal stem cells using beta-tricalcium phosphate-alginate-gelatin hybrid scaffolds. Journal of 
Tissue Engineering and Regenerative Medicine, 1, 417424. doi:10.1002/term.49

[18] Shariatpanahi, R.E., Orang, F., Emami, SH. and Naimi, T. (2006) Cell growth on tissue-engineering scaffolds prepared by gamma irradiation grafting of N-vinyl-2-pyrrolidone onto polyvinyl alcohol. Journal of Biomaterials Science. Polymer Edition, 17, 659-667. doi:10.1163/156856206777346322

[19] Shabani, I., Haddadi-Asl, V., Soleimani, M., Seyedjafari, E., Babaeijandaghi F. and Ahmadbeigi, N. (2011) Enhanced infiltration and biomineralization of stem cells on collagen-grafted three-dimensional nanofibers. Tissue Engineering. Part A, 17, 1209-1218. doi:10.1089/ten.tea.2010.0356

[20] Seyedjafari, E., Soleimani, M., Ghaemi, N. and Shabani, I. (2010) Nanohydroxyapatite-coated electrospun poly(l-lactide) nanofibers enhance osteogenic differentiation of stem cells and induce ectopic bone formation. Biomacromolecules, 11, 3118-3125. doi:10.1021/bm1009238

[21] Pajoum Shariati, S.R., Shokrgozar, M.A., Vossoughi, M. and Eslamifar A (2009) In vitro co-culture of human skin keratinocytes and fibroblasts on a biocompatible and biodegradable scaffold. Iranian Biomedicaal Journal, 13, 169-177.

[22] Hatami, M., Mehrjardi, N.Z., Kiani, S., Hemmesi, K., Azizi, H., Shahverdi, A. and Baharvand, H. (2009) Human embryonic stem cell-derived neural precursor transplants in collagen scaffolds promote recovery in injured rat spinal cord. Cytotherapy, 11, 618-630. doi:10.1080/14653240903005802

[23] Hashemi, S.M., Soleimani, M., Zargarian, S.S., HaddadiAsl, V., Ahmadbeigi, N., Soudi, S., Gheisari, Y., Hajarizadeh, A. and Mohammadi, Y. (2009) In vitro differentiation of human cord blood-derived unrestricted somatic stem cells into hepatocyte-like cells on poly (epsiloncaprolactone) nanofiber scaffolds. Cells Tissues Organs, 190, 135-149. doi: 10.1159/000187716

[24] Nojehdehian, H., Moztarzadeh, F., Baharvand, H., Mehrjerdi, N. Z., Nazarian, H. and Tahriri, M. (2010) Effect of poly-L-lysine coating on retinoic acid-loaded PLGA microspheres in the differentiation of carcinoma stem cells into neural cells. International Journal of Artificial Organs, 33, 721-730.

[25] Baghaban Eslaminejad, M., Taghiyar, L. and Falahi, F. (2009) Quantitative analysis of the proliferation and differentiation of rat articular chondrocytes in alginate 3D culture. Iraniann Biomedical Journal, 13, 153-160.

[26] Nojehdehian, H., Moztarzadeh, F., Baharvand, H., Nazarian, H. and Tahriri, M. (2009) Preparation and surface characterization of poly-L-lysine-coated PLGA microsphere scaffolds containing retinoic acid $\mathrm{n}$ for nerve tissue engineering: In vitro study. Colloids and Surfaces. $B$, Biointerfaces, 73, 23-29. doi:10.1016/j.colsurfb.2009.04.029

[27] Timnak, A., Gharebaghi, F.Y., Shariati, R.P., Bahrami, S.H., Javadian, S., Emami S.H.H., and Shokrgozar MA. (2010) Fabrication of nanostructured electrospun collagen scaffold intended for nerve tissue engineering. Journal of Materials Science. Materials in Medicine, 22, 1555-1567.

\section{doi:10.1007/s10856-011-4316-5}

[28] Azami, M., Samadikuchaksaraei, A. and Poursamar, S.A. (2010) Synthesis and characterization of a laminated hydroxyapatite/gelatin nanocomposite scaffold with controlled pore structure for bone tissue engineering. International Journal of Artificial Organs, 33, 86-95.

[29] Ghazanfari, S., Tafazzoli-Shadpour, M. and Shokrgozar, M.A. (2009) Effects of cyclic stretch on proliferation of mesenchymal stem cells and their differentiation to smooth muscle cells. Biochemical and Biophysical Research Communications, 388, 601-605. doi:10.1016/j.bbrc.2009.08.072

[30] Sharifi, S., Mirzadeh, H., Imani, M., Atai, M., Bakhshi, R. and Ziaee, F. (2006) Synthesis and characterization of novel injectable, biodegradable and in situ crosslinkable poly(hexamethylene-carbonate-fumarate), poly (hexamethylene carbonate) diacrylate and poly(ethylene glycol fumarate-co-hexamethylene carbonate-fumarate) scaffolds for bone tissue engineering. Conference Proceedings: Annual International Conference of the IEEE Engineering in Medicine and Biology Society, 1, 791-794.

[31] Shokrgozar, M.A., Farokhi, M., Rajaei, F., Bagheri, M.H., Azari, S.H., Ghasemi, I., Mottaghitalab, F., Azadmanesh, K. and Radfar, J. (2010) Biocompatibility evaluation of HDPEUHMWPE reinforced $\beta$-TCP nanocomposites using highly purified human osteoblast cells. Journal of biomedical materials research. Part A, 95, 1074-1083. doi:10.1002/jbm.a.32892

[32] Mohammadi, M., Shokrgozar, M. A. and Mofid, R. (2007) Culture of human gingival fibroblasts on a biodegradable scaffold and evaluation of its effect on attached gingiva: A randomized, controlled pilot study. Journal of Periodontology, 78, 1897-1903. doi:10.1902/jop.2007.070083

[33] Homaeigohar, S.S., Shokrgozar, M.A., Javadpour, J., Khavandi, A. and Sadi, A.Y. (2006) Effect of reinforcement particle size on in vitro behavior of beta-tricalcium phosphate-reinforced high-density polyethylene: A novel orthopedic composite. Journal of Biomedical Materials Research. Part A, 78, 129-138. doi:10.1002/jbm.a.31473

[34] Bakhshandeh, B., Soleimani, M., Ghaemi, N. and Shabani, I. (2011) Effective combination of aligned nanocomposite nanofibers and human unrestricted somatic stem cells for bone tissue engineering. Acta pharmacologica Sinica, 32, 626-636. doi:10.1038/aps.2011.8

[35] Seyedjafari, E., Soleimani, M., Ghaemi, N. and Sarbolouki, M. N. (2011) Enhanced osteogenic differentiation of cord blood-derived unrestricted somatic stem cells on electrospun nanofibers. Journal of Materials Science. Materials in Medicine, 22, 165-174. doi:10.1007/s10856-010-4174-6

[36] Akrami, H., Soheili, Z.S., Sadeghizadeh, M., Khalooghi, K., Ahmadieh, H., Kanavi, M.R.,Samiei, S. and Pakravesh, J. ( 2011) Evaluation of RPE65, CRALBP, VEGF, CD68, and Tyrosinase gene expression in human retinal pigment epithelial cells cultured on amniotic membrane. Biochemical genetics, 49, 313-322 doi:10.1007/s10528-010-9409-1

[37] Soleimani, M., Nadri, S. and Shabani, I. (2010) Neurogenic differentiation of human conjunctiva mesenchymal 
stem cells on a nanofibrous scaffold. The International Journal of Developmental Biology, 54, 1295-1300. doi:10.1387/ijdb.092999ms

[38] Mohajeri, S., Hosseinkhani, H., Ebrahimi, N.G., Nikfarjam, L., Soleimani, M. and Kajbafzadeh, A.M. (2011) Proliferation and differentiation of mesenchymal stem cell on collagen sponge reinforced with polypropylene/ polyethylene terephthalate blend fibers. Tissue Engineering Part A, 16, 3821-3830.

doi:10.1089/ten.tea.2009.0520.

[39] Kazemnejad, S., Allameh, A., Soleimani, M., Gharehbaghian, A., Mohammadi, Y, Amirizadehm N. and Jazayery, M. (2009) Biochemical and molecular characterization of hepatocyte-like cells derived from human bone marrow mesenchymal stem cells on a novel threedimensional biocompatible nanofibrous scaffold. Journal of Gastroenterology and Hepatology, 24, 278-287. doi:10.1111/j.1440-1746.2008.05530.x

[40] Niknejad, H., Peirovi, H., Ahmadiani, A., Ghanavi, J. and Jorjani, M. (2010) Differentiation factors that influence neuronal markers expression in vitro from human amniotic epithelial cells. European Cells \& Materials, 19, 22-29.

[41] Behnia, H., Khojasteh, A., Soleimani, M., Tehranchi, A., Khoshzaban, A., Keshel, S.H. and Atashi, R. (2009) Secondary repair of alveolar clefts using human mesenchymal stem cells. Oral Surgery, Oral Medicine, Oral Pathology, Oral Radiology, and Endodontics, 108, 1-6. doi:10.1016/j.tripleo.2009.03.040

[42] Zaminy, A., Ragerdi, K.I., Barbarestani, M., Hedayatpour, A., Mahmoudi, R. and Farzaneh, N.A. (2008) Osteogenic differentiation of rat mesenchymal stem cells from adipose tissue in comparison with bone marrow mesenchymal stem cells: Melatonin as a differentiation factor. Iranian Biomedical Journal, 12, 133-141.

[43] Niknejad, H., Peirovi, H., Jorjani, M., Ahmadiani, A., Ghanavi, J. and Seifalian A.M. (2011) Properties of the amniotic membrane for potential use in tissue engineering. European Cells \& Materials, 29, 88-99.

[44] Shayesteh, Y.S., Khojasteh, A., Soleimani, M., Alikhasi, M., Khoshzaban, A. and Ahmadbeigi, N. (2008) Sinus augmentation using human mesenchymal stem cells loaded into a beta-tricalcium phosphate/hydroxyapatite scaffold. Oral Surgery, Oral Medicine, Oral Pathology, Oral Radiology, and Endodontics, 106, 203-209. doi:10.1016/j.tripleo.2007.12.001

[45] Sharifiaghdas, F., Hamzehiesfahani, N., Moghadasali, R., Ghaemimanesh, F. and Baharvand, H. (2007) Human amniotic membrane as a suitable matrix for growth of mouse urothelial cells in comparison with human peritoneal and omentum membranes. Urology Journal, 4, 7178.

[46] Ahangari, G., Naderimanesh, H., Hossein-Nezhad, A. and Zouali, M.A. (2008) A novel tissue engineering-based assay for immunological infertility. Scandinavian Journal of Immunology, 68, 463-468. doi:10.1111/j.1365-3083.2008.02160.x

[47] Montazeri, N., Jahandideh, R. and Biazar, E. (2011) Synthesis of fluorapatite-hydroxyapatite nanoparticles and toxicity investigations. International Journal of Nanomedicine, 6, 197-201. doi:10.2147/IJN.S15461

[48] Ghasemi-Mobarakeh, L., Prabhakaran, M.P., Morshed, M., Nasr-Esfahani, M.H., Baharvand, H., Kiani, S., Al-Deyab, S.S. and Ramakrishna, S. (2011) Application of conductive polymers, scaffolds and electrical stimulation for nerve tissue engineering. Journal of Tissue Engineering and Regenerative Medicine, 5, 17-35. doi:10.1002/term.383

[49] Asefnejad, A., Behnamghader, A., Khorasani, M.T. and Farsadzadeh, B. (2011) Polyurethane/fluorhydroxyapatite nanocomposite scaffolds for bone tissue engineering. Part I: Morphological, physical, and mechanical characterization. International Journal of Nanomedicine, 6, 93-100. doi:10.2147/IJN.S13385

[50] Sharifiaghdas, F., Moghadasali, R., Baharvand, H., Hosseini-Moghaddam, S.M. and Mahmoudnejad, N. (2009) Special characteristics of culturing mature human bladder smooth muscle cells on human amniotic membrane as a suitable matrix. Urology Journal, 6, 283-288.

[51] Aboudzadeh, N., Imani, M., Shokrgozar, M.A., Khavandi, A., Javadpour, J., Shafieyan, Y. and Farokhi, M. (2010) Fabrication and characterization of poly(D,L-lactide-coglycolide)/hydroxyapatite nanocomposite scaffolds for bone tissue regeneration. Journal of Biomedical Materials Research. Part A, 94, 137-145. doi:10.1002/jbm.a.32673

[52] Zandi, M., Mirzadeh, H., Mayer, C., Urch, H., Eslaminejad, M.B., Bagheri, F. and Mivehchi, H. (2010) Biocompatibility evaluation of nano-rod hydroxyapatite/gelatin coated with nano-HAp as a novel scaffold using mesenchymal stem cells. Journal of Biomedical Materials Research. Part A, 92, 1244-1255. doi:10.1002/jbm.a.32452

[53] Sharifi, S., Imani, M., Mirzadeh, H., Atai, M., Ziaee, F. and Bakhshi, R. (2009) Synthesis, characterization, and biocompatibility of novel injectable, biodegradable, and in situ crosslinkable polycarbonatebased macromers. Journal of Biomedical Materials Research. Part A, 90, 830-843. doi:10.1002/jbm.a.32138

[54] Atala, A. (2007) Engineering tissues, organs and cells. Journal of Tissue Engineering and Regenerative Medicine, 1, 83-96 doi:10.1002/term.18

[55] Khodadadi, L., Shafieyan, S., Sotoudeh, M., Dizaj, A. V., Shahverdi, A., Aghdami, N. and Baharvand, H. (2010) Intra-epidermal injection of dissociated epidermal cell suspension improves vitiligo. Archives of Dermatological Research, 302, 593-599. doi:10.1007/s00403-010-1034-7

[56] Polak, J.M. and Bishop A.E. (2006) Stem cells and tissue engineering: Past, present, and future. Annals of the New York Academy of Sciences, 1068, 352-366 doi:10.1196/annals.1346.001

[57] Watt, F.M and Hogan, B.L.M. (2000) Out of Eden: Stem cells and their niches. Science, 287, 1427-1430 doi: 10.1126/science.287.5457.1427

[58] Biancho, P. and Robey, P.G. (2000) Marrow stromal stem cells. The Journal of Clinical Investigation, 105, 16631668. doi:10.1172/JCI10413

[59] Shafiee, A., Seyedjafari, E., Soleimani, M., Ahmadbeigi, 
N., Dinarvand, P. and Ghaemi, N. (2011) comparison between osteogenic differentiation of human unrestricted somatic stem cells and mesenchymal stem cells from bone marrow and adipose tissue. Biotechnology Letter, 33, 1257-1264. doi:10.1007/s10529-011-0541-8

[60] Ghaedi, M., Soleimani, M., Taghvaie, N. M., Sheikhfatollahi, M., Azadmanesh, K., Lotfi, A.S. and Wu, J. (2011) Mesenchymal stem cells as vehicles for targeted delivery of anti-angiogenic protein to solid tumors. The Journal of Gene Medicine, 13, 171-180. doi:10.1002/jgm.1552

[61] Ghaedi, M., Tuleuova, N., Zern, M.A., Wu, J. and Revzin, A. (2011) Bottom-up signaling from HGF containing surfaces promotes hepatic differentiation of mesenchymal stem cells. Biochemical and Biophysical Research Communications, 407, 295-300. doi:10.1016/j.bbrc.2011.03.005

[62] Ahmadbeigi, N., Shafiee, A., Seyedjafari, E., Gheisari, Y., Vassei, M., Amanpour, S., Amini, S., Bagherizadeh, I. and Soleimani, M. (2011) Early spontaneous immortalization and loss of plasticity of rabbit bone marrow mesenchymal stem cells. Cell Proliferation, 44, 67-74. doi:10.1111/j.1365-2184.2010.00731.x

[63] Dinarvand, P., Hashemi, S.M. and Soleimani, M. (2010) Effect of transplantation of mesenchymal stem cells induced into early hepatic cells in streptozotocin-induced diabetic mice. Biological \& Pharmaceutical Bulletin, 33, 1212-1217. doi:10.1248/bpb.33.1212

[64] Taha, M.F. and Hedayati V. (2010) Isolation, identification and multipotential differentiation of mouse adipose tissue-derived stem cells. Tissue Cell, 42, 211-216. doi:10.1016/j.tice.2010.04.003

[65] Ghasemi-Mobarakeh, L., Morshed, M., Karbalaie, K., Fesharaki, M.A., Nematallahi, M., Nasr-Esfahani, M.H. and Baharvand, H. (2009) The thickness of electrospun poly (epsilon-caprolactone) nanofibrous scaffolds influences cell proliferation. The International Journal of Artificial Organs, 32, 150-158.

[66] Nadri, S., Soleimani, M., Mobarra, Z. and Amini, S. (2008) Expression of dopamine-associated genes on conjunctiva stromal-derived human mesenchymal stem cells. Biochemical and Biophysical Research Communications, 377, 42342-8. doi:10.1016/j.bbrc.2008.09.148

[67] Mohammadi, Y., Soleimani, M., Fallahi-Sichani, M., Gazme, A., Haddadi-Asl, V., Arefian, E., Kiani, J., Moradi, R., Atashi, A. and Ahmadbeigi, N. (2007) Nanofibrous poly(epsiloncaprolactone)/poly(vinyl alcohol)/chitosan hybrid scaffolds for bone tissue engineering using mesenchymal stem cells. The International Journal of Artificial Organs, 30, 204-211.

[68] Gharibani, P.M., Tiraihi, T. and Arabkheradmand, J. (2010) In vitro differentiation of GABAergic cells from bone marrow stromal cells using potassium chloride as inducer. Restorative Neurology and Neuroscience, 28, 367-377. doi:10.3233/RNN-2010-0539

[69] Baharvand, H., Mehrjardi, N.Z., Hatami, M., Kiani, S., Rao, M. and Haghighi, M.M. (2007) Neural differentiation from human embryonic stem cells in a defined adherent culture condition. The International Journal of Developmental Biology, 51, 371-378.

\section{doi: 10.1387/ijdb.072280hb}

[70] ASTM F2150-07 (2007) Standard guide for characterization and testing of biomaterial scaffolds used in tissueengineered medical products.

[71] Chen, G., Ushida, T. and Tateishi, T. (2002) Scaffold design for tissue engineering. Macromolecular Bioscience, 2, 67-77. doi:10.1002/1616-5195(20020201)

[72] Hersel, U., Dahmen, C. and Kessler H. (2003) RGD modified polymers: Biomaterials for stimulated cell adhesion and beyond. Biomaterials, 24, 4385-4415. doi:10.1016/S0142-9612(03)00343-0

[73] Chan, B.P. and Leong, K.W. (2008) Scaffolding in tissue engineering: general approaches and tissue-specific considerations. European Spine Journal, 17, S467-S479. doi:10.1007/s00586-008-0745-3

[74] Heidarkhan, Tehrani, A., Zadhoush, A., Karbasi, S. and Sadeghi-Aliabadi, H. (2010) Scaffold percolative efficiency: In vitro evaluation of the structural criterion for electrospun mats. Journal of Materials Science. Materials in Medicine, 21, 2989-2998. doi:10.1007/s10856-010-4149-7

[75] Shahhosseini, R., Asadifard, F., Enayatollahi, M., Shapourgan, M., Haghjo R. and Heidari Keshel, S. (2010) Nanometric grafting of poly(N-isopropylacrylamide) onto polystyrene film by different doses of gamma radiation. International Journal of Nano Dimension, 1, 77-88.

[76] Biazar, E., Montazeri, N., Pourshamsian, K., Asadifard, F., Ghorbanalinezhad, E., Heidari Keshel. S., Hashemi, M., Rahbar, S. and Majdi, A. (2010) Harvesting epithelial cell sheet based on thermo-sensitive hydrogel. Journal of Paramedical Sciences, 1, 27-33.

[77] Babaeijandaghi, F., Shabani, I., Seyedjafari, E., Naraghi, Z.S., Vasei, M., Haddadi-Asl, V., Hesari, K.K. and Soleimani, M. (2010) Accelerated epidermal regeneration and improved dermal reconstruction achieved by polyethersulfone nanofibers. Tissue engineering. Part A, 16, 3527-3536. doi:10.1089/ten.tea.2009.0829.

[78] Hajiali, H., Karbasi, S., Hosseinalipour, M. and Rezaie, H.R. (2010) Preparation of a novel biodegradable nanocomposite scaffold based on poly(3-hydroxybutyrate)/ bioglass nanoparticles for bone tissue engineering. Journal of Materials Science. Materials in Medicine, 21 2125-2132. doi:10.1007/s10856-010-4075-8

[79] Eslaminejad, M.B., Mirzadeh, H., Mohamadi, Y. and Nickmahzar, A. (2007) Bone differentiation of marrowderived mesenchymal stem cells using beta-tricalcium phosphate-alginate-gelatin hybrid scaffolds. Journal of Tissue Engineering and Regenerative Medicine, 1, 4174124. doi:10.1002/term.49

[80] Chung, C. and Burdick, J.A. (2008) Engineering cartilage tissue. Advanced Drug Delivery Reviews, 60, 243-262/ doi:10.1016/j.addr.2007.08.027

[81] Orazizadeh, M., Lee, H.S., Groenendijk, B., Sadler, S.J., Wright, M.O., Lindberg, F.P. and Salter, DM. (2008) CD47 associates with alpha 5 integrin and regulates responses of human articular chondrocytes to mechanical stimulation in an in vitro model. Arthritis Research Therapy, 10, R4. doi:10.1186/ar2350 
[82] Orazizadeh, M., Cartlidge, C., Wright, M.O., MillwardSadler, S.J., Nieman, J., Halliday, B.P., Lee, H.S. and Salter, D.M. (2006) Mechanical responses and integrin associated protein expression by human ankle chondrocytes. Biorheology, 43, 249-258.

[83] Orazizadeh, M. and Salter, D.M. (2007) The expression of signal regulatory protein-alpha in normal and osteoarthritic human articular cartilage and its involvement in chondrocyte mechano-transduction response. Iranian Biomedical Journal, 11, 119-124.

[84] Makoolati, Z., Movahedin, M. and Forouzandeh-Moghadam, M. (2011) Bone morphogenetic protein 4 is an efficient inducer for mouse embryonic stem cell differentiation into primordial germ cell. In Vitro Cellular \& Developmental Biology. Animal, 47, 391-398 doi: 10.1007/s11626-011-9404-9

[85] Freed, L.E. and Vunjak-Novakovic, G. (2000) Tissue engineering bioreactors. In: Lanza, R.P., Langer, R. and Vacanti, J., Eds., Principles of Tissue Engineering, Academic Press, San Diego, 143-156.

[86] Golmakany, N., Rasaee, M.J., Furouzandeh, M., Sho- jaosadati, S.A., Kashanian, S. and Omidfar, K. (2005) Continuous production of monoclonal antibody in a packed-bed bioreactor. Biotechnology and Applied Biochemistry, 41, 273-278. doi:10.1042/BA20040121

[87] Amoabediny, G., Abbas, M. P. and Büchs, J. (2010) Determination of $\mathrm{CO}_{2}$ sensitivity of microorganisms in shaken bioreactors. II. Novel online monitoring method. Biotechnology and applied biochemistry, 57, 167-175. doi:10.1042/BA20100212

[88] Amoabediny, G. and Büchs, J. (2010) Determination of $\mathrm{CO}_{2}$ sensitivity of micro-organisms in shaken bioreactors. I. Novel method based on the resistance of sterile closure. Biotechnology and Applied Biochemistry, 57, 157-166. doi:10.1042/BA20100211

[89] Amoabediny, G., Ziaie-Shirkolaee, Y. and Büchs, J. (2009) Development of an unsteady-state model for a biological system in miniaturized bioreactors. Biotechnology and Applied Biochemistry, 54, 163-170. doi:10.1042/BA20090141 